\title{
The complexities of wildfires
}

\author{
Wildfires are a natural part of many ecosystems, but they can become destructive and less predictable, especially \\ when the system is perturbed. Human activities and climate change lead to interactions with fire dynamics that \\ need our attention.
}

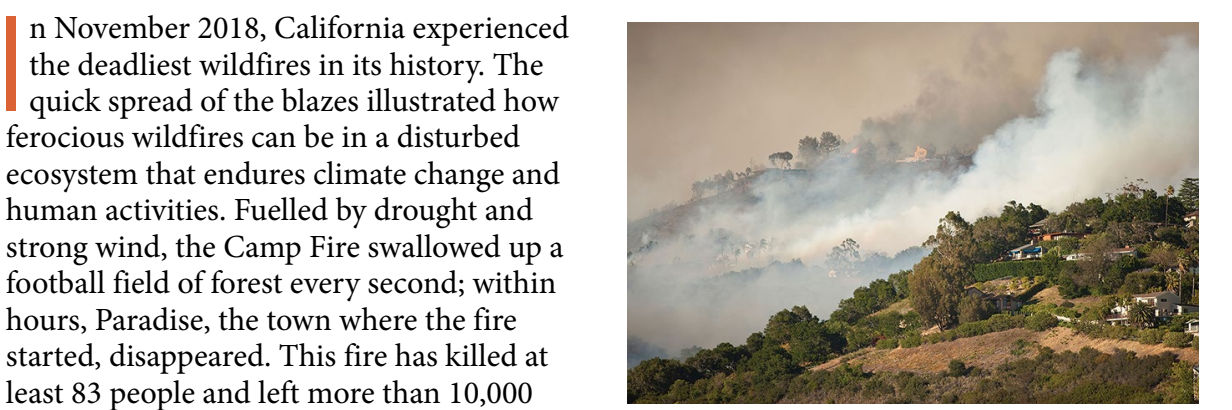

homes destroyed ${ }^{1}$. Fires raged not only in California. In 2018, British Columbia experienced an unusual areal extent of burning. Wildfires may have become more vigorous as the climate warms. But the trend of fire risk is a complex puzzle of changes in ecosystems and climate as well as human activities. In this issue, an Article by Bowd et al., an Article by Marrs et al. and an accompanying web focus (https:// www.nature.com/collections/jchbhhagcb/) explore the trends and impacts of wildfires in ecosystems disturbed by climate change and human activities.

Wildfire is a natural component of the Earth system. Naturally occurring fires are important for vegetation growth. Periodical burning helps to curb the accumulation of dead and fire-prone vegetation and to release the nutrients stored in the litter on the forest floor. In undisturbed ecosystems in a steady-state climate, a dynamic balance between wildfire burning and vegetation growth is established. Wildfire shapes vegetation patterns by influencing vegetation height, biomass and dominant function. Fire-shaped vegetation landscapes, as a result, are less prone to the intense fire break-outs that may devastate local ecosystems. Many indigenous people around world have been using fire as a tool to manage land for thousands of years, perhaps inspired by these processes in nature.

Fire affects vegetation, soil and water resources ${ }^{2}$. Anthropogenic climate change can exacerbate the impacts of fire, as it can increase mortality of the woody vegetation, speed up the accumulation of fuel for wildfires $^{3}$ and help fires to spread faster ${ }^{4}$.
Credit: Chuck Place / Alamy Stock Photo

Long-term satellite observations suggest that fire seasons are lengthening 5 .

The interactions between fires and climate change may continue to alter fire characteristics. For example, peatlands ${ }^{6}$ and rainforests ${ }^{7}$, two vast terrestrial carbon sinks, release large amounts of carbon during fires, and thereby fuel climate change. $\mathrm{CO}_{2}$ emissions from the drought-related fires in Amazon forests between 2003 and 2015 were comparable to those from local deforestation over the same period.

Human impacts on fire risk can go both ways. A global analysis of satellite data over the past 18 years shows that areas burned by wildfire have declined ${ }^{8}$. This trend is primarily a result of agricultural expansion and intensification, which make the vegetation landscape less flammable. But at the same time, humans have raised fire risk in some regions. In the United States, human-started wildfires, accounting for $84 \%$ of all wildfires between 1992 and 2012, lasted three times longer than naturally occurring fires and also affected much broader areas 9 . In fact, humans seem to play an important role in the most destructive wildfires. According to an analysis of more than 20 million wildfire cases between 2002 and 2013, the most economically or socially disastrous wildfires are concentrated at the transition between wildland and urban areas $^{10}$. The devastating November 2018 fires in California were also reported to be ignited in such a transition region.
Conscious and unconscious land management practices by humans may lead to different outcomes for ecosystems. For example, on the one hand, Bowd et al. show that human disturbances, such as forest logging, may further intensify the impacts of wildfires on Australia's mountain ash forests. On the other hand, proactive fire management practices, such as controlled burning, can make wildlands less prone to outbreaks of devastating fires. Such practices will need comprehensive assessments over the long term. For instance, Marrs et al. show that long-term prescribed burning with a gradient of frequency in a fire-managed peatland in the United Kingdom did not prevent peat and carbon accumulations, but each additional burn reduced the accumulation rates by $4.9 \mathrm{~g} \mathrm{~m}^{-2} \mathrm{yr}^{-1}$ and $1.9 \mathrm{~g} \mathrm{C} \mathrm{cm}^{-2} \mathrm{yr}^{-1}$, respectively.

In the wake of California's deadly fires, the debate on the role of humans in fire management has escalated in US social media. The issue is far more than a political trivia: a fire out of hand is a threat to lives and livelihoods. There is in fact no one-size-fits-all answer for different regions. The complexities of wildfire dynamics and their interactions with human interference and climate change are such that each region and ecosystem must be studied in its own right.

Published online: 30 January 2019 https://doi.org/10.1038/s41561-019-0311-0

\footnotetext{
References

1. California wildfires: Camp Fire nearly fully contained. $B B C$ News (23 November 2018); https://www.bbc.com/news/world-uscanada-46315029

2. Neary, D. G., Ryan, K. C. \& DeBano, L. F. (eds) Wildland Fire in Ecosystems: Effects of Fire on Soils and Water General Technical Report RMRS-GTR-42-volume 4 (US Department of Agriculture, Forest Service, Rocky Mountain Research Station, 2005).

3. Marlon, J. R. et al. Proc. Natl Acad. Sci. USA 106, 2519-2524 (2009).

4. Yue, X. et al. Atmos. Chem. Phys. 15, 10033-10055 (2015).

5. Jolly, W. M. et al. Nat. Commun. 6, 7537 (2015).

6. Turetsky, M. R. et al. Nat. Geosci. 8, 11-14 (2015).

7. Aragão, L. E. O. C. et al. Nat. Commun. 9, 536 (2018).

8. Andela, N. et al. Science 356, 1356-1362 (2017).

9. Balch, J. K. et al. Proc. Natl Acad. Sci. USA 114, 2946-2951 (2017).

10. Bowman, D. M. J. S. et al. Nat. Ecol. Evol. 1, 0058 (2017).
} 